\title{
The Application of Attenuated Total Reflection Infrared Spectroscopy to Investigate the Liquid Phase Hydrogenation of Benzaldehyde Over an Alumina-Supported Palladium Catalyst
}

\author{
Cédric Boulho ${ }^{1} \cdot$ Emma K. Gibson $^{1} \cdot$ Mairi I. McAllister $^{1} \cdot$ Robert Moss $^{1} \cdot$ David Lennon $^{1}$ (D)
}

Published online: 18 July 2020

(c) The Author(s) 2020

\begin{abstract}
The hydrogenation of benzaldehyde in cyclohexane over a $5 \mathrm{wt} \% \mathrm{Pd} / \mathrm{Al}_{2} \mathrm{O}_{3}$ catalyst at $313 \mathrm{~K}$ is firstly investigated at ambient pressure in a stirred batch reactor. The formation of benzyl alcohol is a facile process and a small mass imbalance is indirectly attributed to the formation of benzene as a by-product. No hydrogenolysis reaction to form toluene is observed. Secondly, examination of this reaction system by attenuated total reflection infrared (ATR-IR) spectroscopy enables the chemistry at the liquid/solid interface to be probed. Specifically, the $\nu(C=O)$ modes of solvated and adsorbed benzaldehyde are evident at 1712 and $1691 \mathrm{~cm}^{-1}$ respectively, providing information on how the reagent is partitioning within the reaction medium. Spectral acquisition on initiation of hydrogenation then enables the benzaldehyde $\rightarrow$ benzyl alcohol transition to be tracked. The additional presence of a broad CO stretching band of chemisorbed carbon monoxide $\left(1852-1929 \mathrm{~cm}^{-1}\right)$ is attributed to the hydrogen-assisted decarbonylation pathway that forms the benzene by-product.
\end{abstract}

Keywords Alumina-supported Pd catalyst $\cdot$ Liquid phase hydrogenation of benzaldehyde $\cdot$ Attenuated total reflection infrared spectroscopy

\section{Introduction}

The heterogeneously catalysed liquid phase hydrogenation of benzaldehyde has been reported over several metals and supports [1-4]. The hydrogenation product of this reaction, benzyl alcohol, is an important chemical having a wide range of commercial applications, including use as a solvent, inks and paints, and as a precursor in the production of cosmetics and flavourings [1,5]. Whilst the catalytic hydrogenation of benzaldehyde is a viable route to benzyl alcohol, achieving a high selectivity can be problematic [6].

The observed product distribution is dependent on several factors including metal, support, solvent and reaction conditions [1]. As such, it is essential to acknowledge the full suite of reactions possible during the hydrogenation of benzaldehyde to benzyl alcohol. For example, upon formation, the benzyl alcohol may undergo further reaction in the

David Lennon

David.Lennon@glasgow.ac.uk

1 School of Chemistry, Joseph Black Building, University of Glasgow, Glasgow G12 8QQ, UK form of hydrogenolysis to yield toluene. Hydrogenolysis is particularly prevalent over Group VIII metals (Ni, Pd and Pt) $[1,7,8]$, and in the presence of reducible oxides, such as titania and zirconia, as they favour interaction with the hydroxyl oxygen [1]. Moreover, in particular with Ni based catalysts, ring hydrogenation is also possible $[3,4]$, resulting in production of species such as methylcyclohexane, cyclohexylmethanol and cyclohexane [3, 4]. Selection of a suitable metal is, however, a compromise. Whilst not typically employed as a hydrogenation catalyst, supported $\mathrm{Au}$ catalysts are reported to result in enhanced performance in terms of selectivity towards benzyl alcohol $[1,9]$. Nevertheless, significantly lower hydrogenation rates are observed than for conventional hydrogenation metal catalysts such as $\mathrm{Pd}$ and Ni $[1,9]$. Depending on the solvent used for the reaction, interactions with the solvent can also occur. This is particularly prevalent for polar solvents such as alcohols $[1,2,7]$. For example, using ethanol, (ethoxymethyl)benzene and (diethoxymethyl)benzene can be produced [1].

For liquid phase heterogeneously catalysed hydrogenation reactions there exists an equilibrium between the catalyst surface and the liquid phase, connecting reactants, intermediates and products. Attenuated total reflection 
infrared (ATR-IR) spectroscopy has received significant interest over the last two decades, where the technique has been used to study a variety of catalytic reactions due to its ability to monitor the adsorbed species in the presence of the solution phase $[10,11]$. Whilst the focus of this study is a hydrogenation reaction, there is also significant literature on the reverse reaction, alcohol oxidation $[12,13]$. Indeed, ATR-IR studies relating to benzyl alcohol oxidation provide useful spectroscopic markers and insights that are highly relevant to the hydrogenation of benzaldehyde [14, 15].

In recent years several liquid phase reactions over heterogeneous catalysts have been investigated by ATR-IR. Both adsorption and dissociation, oxidation and, hydrogenation studies have been probed. A focus of much of these in situ studies has been the search for reaction intermediates to elucidate reaction mechanisms $[10,11$, 15-21]. Here, we focus on the ability of ATR-IR spectroscopy to provide molecular speciation on the solid (catalyst)-liquid interface; a region frequently troubled by mass transport limitations [22].

This communication applies ATR-IR spectroscopy to examine the liquid phase hydrogenation of benzaldehyde, with outcomes rationalised within a range of accessible reaction pathways. Palladium is selected as the metal catalyst and cyclohexane is selected as a reaction solvent. Scheme 1 summarises the chemical pathways associated with this reaction system which are potentially accessible.

Scheme 1 highlights that the primary reaction is hydrogenation of benzaldehyde to afford benzyl alcohol. The benzyl alcohol may then experience hydrogenolysis of the hydroxyl functionality to yield toluene. In addition, the formation of benzene, via either a decarbonylation or a hydrogenolysis pathway, is possible. In order to validate the observed product distribution from the ATR-IR spectroscopic studies the reaction was also performed in a batch reactor.

\section{Experimental}

\subsection{Liquid Phase Ambient Pressure Reactor}

Using a Radleys 6 port carousel stirrer hotplate with condenser, the liquid phase hydrogenation of benzaldehyde over a 5\% $\mathrm{Pd} / \mathrm{Al}_{2} \mathrm{O}_{3}$, (Alpha Aesar, 11713) was tested at ambient pressure. $20 \mathrm{~mL}$ of cyclohexane (Fischer Scientific, reagent grade) was first degassed under $\mathrm{N}_{2}$, prior to addition of the catalyst $(\sim 18 \mathrm{mg})$. Catalyst reduction was performed at $313 \mathrm{~K}$, under $\mathrm{H}_{2}$ flow $(20 \mathrm{~mL} / \mathrm{min})$ for $60 \mathrm{~min}$. Following reduction and maintaining the temperature at $313 \mathrm{~K}$, the reaction was commenced by the introduction of benzaldehyde ( $200 \mu \mathrm{L}, 0.07 \mathrm{M}$, Sigma Aldrich, 99.5\%). The addition of the benzaldehyde was taken as time $\mathrm{t}_{0}$. Samples were extracted (approximately $0.25 \mathrm{~mL}$ ) for gas-liquid chromatography (GLC) measurement (Agilent 6850 GC fitted with a DB-5 capillary column and a flame ionisation detector) at regular intervals over a period of $60 \mathrm{~min}$. An internal standard, n-decane (0.1 M, Sigma Aldrich, purity $\geq 95 \%)$ was added to the samples to aid quantification. GC was used to determine the concentration of benzaldehyde, benzyl alcohol and toluene.

Cyclohexane was selected as a reaction solvent on three grounds: (i) it is stable concerning the possibility of further hydrogenation; (ii) it exhibits discrete spectral features in the infrared spectrum that provide access to reagent/product vibrational bands $[v(\mathrm{C}=\mathrm{O})$ of $\mathrm{R}-(\mathrm{C}=\mathrm{O}) \mathrm{H}, \mathrm{v}(\mathrm{C}-\mathrm{O})$ of $\mathrm{R}-\mathrm{OH}$ and $\left[\nu(\mathrm{C}=\mathrm{O})\right.$ of $\left.(\mathrm{CO})_{\mathrm{ad}}\right]$; and (iii) the mole fraction for hydrogen in cyclohexane at 1 bar and $298 \mathrm{~K}$ is $4.1 \times 10^{-4}$, which compares favourably with a typical hydrogenation solvent such as methanol $\left(1.6 \times 10^{-4}\right)[23]$.

\subsection{Ambient Pressure ATR-FTIR Reactions}

A 10 bounce horizontal ATR heated flow through cell from Pike Technologies, with a $80 \times 10 \times 4 \mathrm{~mm}$ germanium internal reflection element (IRE) was used for the ATR
Scheme 1 Generic reaction scheme for the heterogeneously catalysed hydrogenation of benzaldehyde

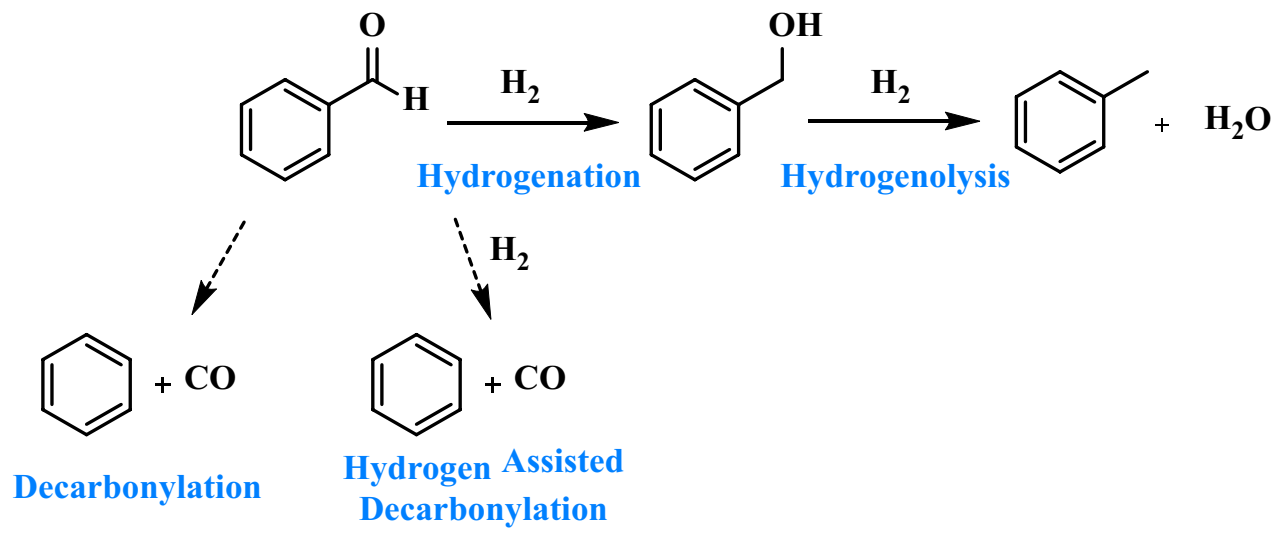


measurements. The ATR cell was mounted in a Bruker Tensor II FTIR spectrometer equipped with a MCT detector. Reference solutions were recorded using 128 scans (acquisition time $=$ approximately $4 \mathrm{~min}$ ), whereas reaction spectra were recorded using 16 scans (acquisition time $=$ approximately $30 \mathrm{~s}$ ). The reduced acquisition time associated with the lower number of scans ensures that the analysis of the reaction is as close to 'real time' as possible.

The catalyst, $50 \mathrm{mg}$, was adhered to the Ge IRE using the following procedure. The catalyst was first ground then sonicated in a small volume of water $(4 \mathrm{~mL})$ for $3 \mathrm{~h}$ to achieve a slurry like paste. A small volume of the slurry was subsequently added dropwise to the IRE, then dried at $333 \mathrm{~K}$ in air (using the ATR reactor heater). This additiondrying procedure was repeated until approximately $50 \mathrm{mg}$ of catalyst had been added to the IRE and a uniform coating achieved.

Following the catalyst deposition stage, cyclohexane was flowed through the cell. A flow of hydrogen was then introduced, allowing the catalyst to be reduced prior to the collection of a background spectrum at reaction temperature (313 K), and used for all subsequent measurements.

The ATR flow set-up was a closed loop system comprising a small sample tube containing the reaction solution (40 mL, $0.07 \mathrm{M}$ benzaldehyde in cyclohexane) fitted with a gas bubbler. The solutions was flowed through the ATR cell. A Gilson MiniPuls 3 peristaltic pump maintained a flow rate of $1.1 \mathrm{~mL} / \mathrm{min}$. After reduction of the catalyst, a helium degassed solution of benzaldehyde was passed over the catalyst until the FTIR signal stabilised. The $\mathrm{H}_{2}$ flow $(20 \mathrm{~mL} / \mathrm{min}$ ) was then switched on, this was taken as the starting point of reaction time, $t_{0}$. Figure 1 shows a schematic representation of the ATR-IR hydrogenation set-up.

During the gas flow process no obvious loss of catalyst was observed and on inspection of the ATR element post reaction the catalyst film appeared intact. Moreover, infrared spectra recorded over the full reaction coordinate exhibited comparable baseline intensities. These observations indicate the catalyst film to have been relatively unperturbed during the reaction sequence.

Operating the ATR cell in a continuous flow mode was intended to provide the opportunity for multiple regent/ catalyst interactions, as would be the case in the batch reactor. However, it is acknowledged that the reported ATR-IR set-up (Fig. 1) does not represent ideal hydrogenation conditions; not least presenting inefficient mixing and a limited supply of dissolved hydrogen. Thus, the described arrangements are providing vibrational spectroscopic information of an established hydrogenation reaction under conditions of constrained hydrogen supply, i.e. a scenario not totally unknown in liquid phase heterogeneously catalysed reactions.

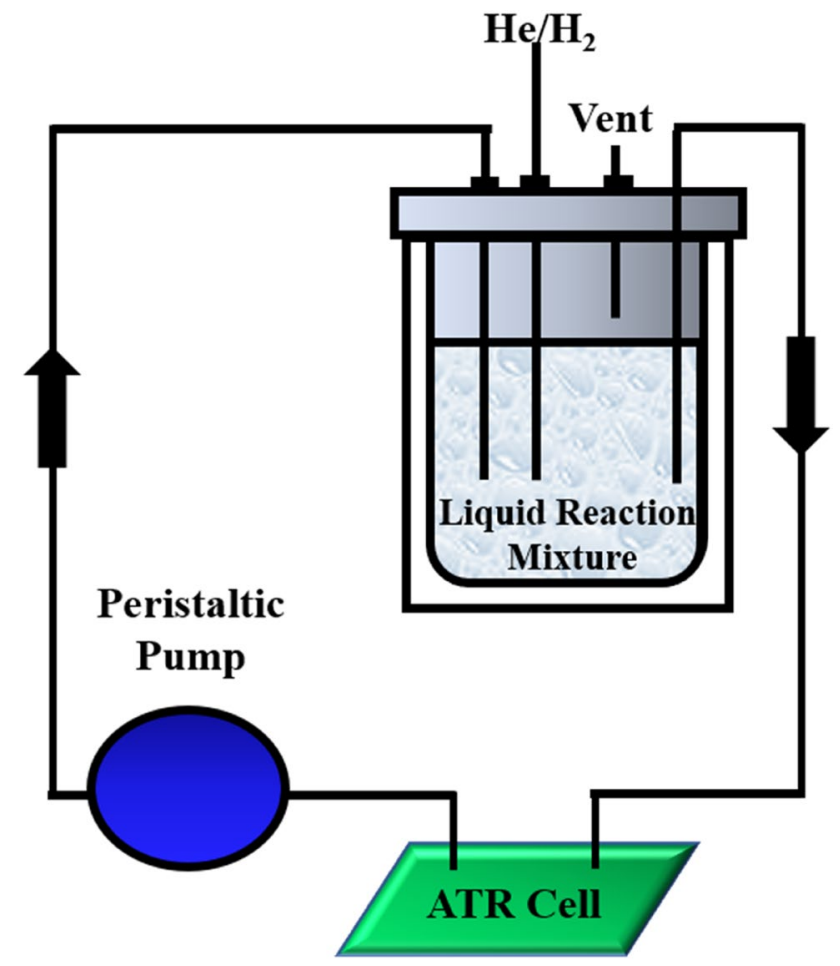

Fig. 1 Schematic representation of the ATR-IR hydrogenation set-up

\section{Results}

\subsection{Stirred Batch Reactor}

The reaction profile for benzaldehyde hydrogenation in the stirred batch reactor is presented in Fig. 2. Benzaldehyde conversion is complete within $60 \mathrm{~min}$ and benzyl alcohol is identified as the primary product ( $\sim 79 \%$ yield). However, Fig. 2 also represents a significant mass imbalance that represents $\sim 21 \%$ on reaction completion. For the experimental arrangement used, no other products were identified. Toluene was readily detectable by the GLC but this molecule was absent from the reaction mixture. Unfortunately, benzene (B.Pt. 353.1 K) could not be resolved from the process solvent (cyclohexane, B.Pt. 353.8 K). However, with reference to Scheme 1 , the mass imbalance is tentatively attributed to the coincident formation of benzene as a by-product. Importantly, Fig. 2 establishes that benzaldehyde hydrogenation over this particular catalyst is facile, and that this reaction system is suitable for further investigation by ATR-IR.

\subsection{ATR-IR: The Carbonyl Stretch of Benzaldehyde}

Figure $3 \mathrm{a}$ presents the ATR-IR spectrum in the region $1600-1800 \mathrm{~cm}^{-1}$ as the benzaldehyde/cyclohexane solution is passed over the $\mathrm{Pd} / \mathrm{Al}_{2} \mathrm{O}_{3}$ catalyst at $313 \mathrm{~K}$ in the presence of helium gas. Two peaks are seen about $1700 \mathrm{~cm}^{-1}$. 


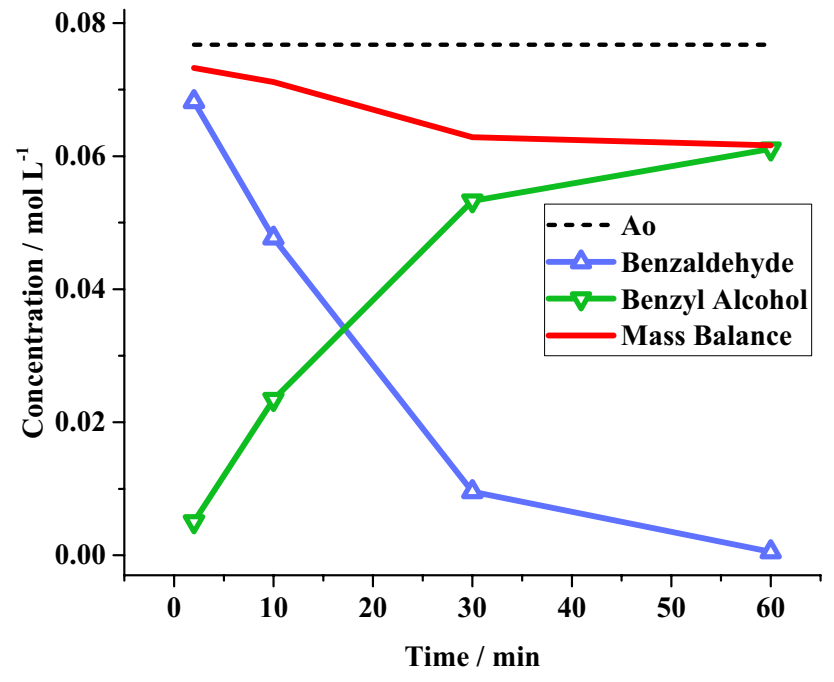

Fig. 2 Reaction profile for the liquid phase hydrogenation of benzaldehyde $(0.2 \mathrm{~mL})$ conducted in the stirred batch reactor over $5 \mathrm{wt} \%$ $\mathrm{Pd} / \mathrm{Al}_{2} \mathrm{O}_{3}$ catalyst $(17.4 \mathrm{mg})$ at $313 \mathrm{~K}$ in cyclohexane $(20 \mathrm{~mL})$

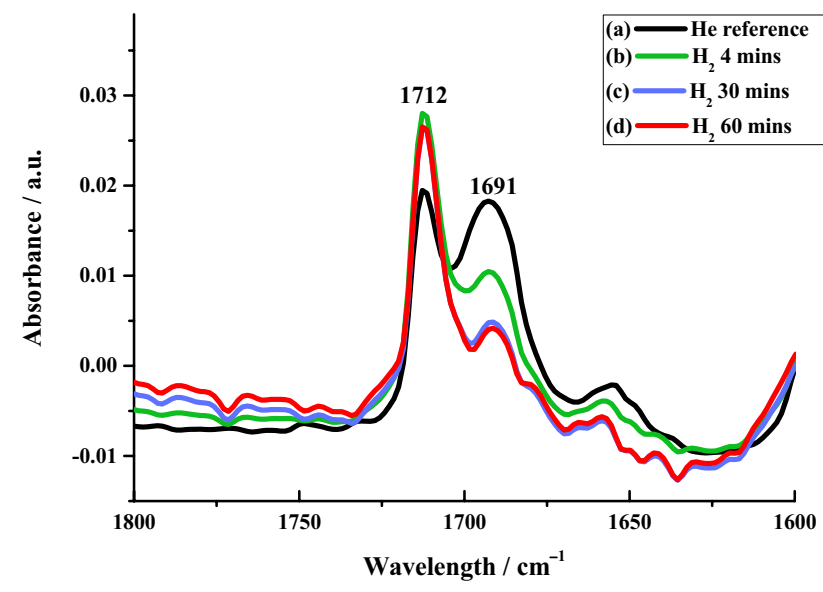

Fig. 3 (a) ATR-IR spectrum $\left(1600-1800 \mathrm{~cm}^{-1}\right)$ for the interaction of benzaldehyde in cyclohexane over a $5 \mathrm{wt} \% \mathrm{Pd} / \mathrm{Al}_{2} \mathrm{O}_{3}$ catalyst $(50 \mathrm{mg}$ ) at $313 \mathrm{~K}$ in the presence of flowing helium and after a reduction stage. The helium flow was stopped and replaced with hydrogen gas; the spectrum was monitored as a function of time-on-stream: (b) 4 , (c) 30 and (d) $60 \mathrm{~min}$

The narrower feature at $1712 \mathrm{~cm}^{-1}$ is assigned to solvated benzaldehyde, whilst the broader band centred at $1691 \mathrm{~cm}^{-1}$ is assigned to benzaldehyde adsorbed to the catalyst surface. In this way, Fig. 3a is sampling the equilibrium between solvated and adsorbed benzaldehyde.

In a recent study of the oxidation of benzyl alcohol by Campisi et al., the benzaldehyde product was shown to adsorb to the catalyst surface at a similar wavenumber to that reported here [14]. Moreover, in a study conducted by Liu and co-workers examining the hydrogenation of cinnamaldehyde over Pt/MIL-101, a comparable shift to that observed in this work is detected upon adsorption of the aldehyde. Other than stating that it was not likely to be the rate determining step, that study did not explicitly consider the adsorption equilibria further [20].

Hydrogen was substituted for helium, initiating the hydrogenation reaction and the IR spectra recorded as a function of time-on-stream (Fig. 3b-d). The introduction of hydrogen gas induces changes in intensity of both of the $v(C=O)$ bands.

The integrated intensities of both free and adsorbed benzaldehyde bands are presented in Fig. 4, showing the intensity changes as the reaction proceeds (Fig. 4a, b). In addition, total peak area has been plotted, i.e. benzaldehyde (solv) plus benzaldehyde (ads), (Fig. 4c) that is representative of benzaldehyde conversion.

At short reaction times, i.e. $\mathrm{t}=4 \mathrm{~min}$, there is the expected decrease in intensity of the adsorbed benzaldehyde peak as it is hydrogenated to product but, somewhat unexpectedly, there is a concomitant increase in intensity of the feature attributed to solvated benzaldehyde. It is proposed that upon introduction of the hydrogen co-feed, hydrogen dissociatively adsorbs onto the catalyst surface, forcing some of the weakly adsorbed benzaldehyde off the surface and into solution. This scenario is indicative of a competitive adsorption system. Thereafter, the hydrogenation reaction proceeds, as evidenced in Fig. 4 by a decline in both free and adsorbed benzaldehyde after 4 min T-o-S. As presented, the ATR-IR measurements are qualitative. Nevertheless, on the assumption that Fig. $4 \mathrm{c}$ is indicative of total benzaldehyde conversion, at $60 \mathrm{~min}$ this corresponds to $\sim 14.5 \%$ conversion.

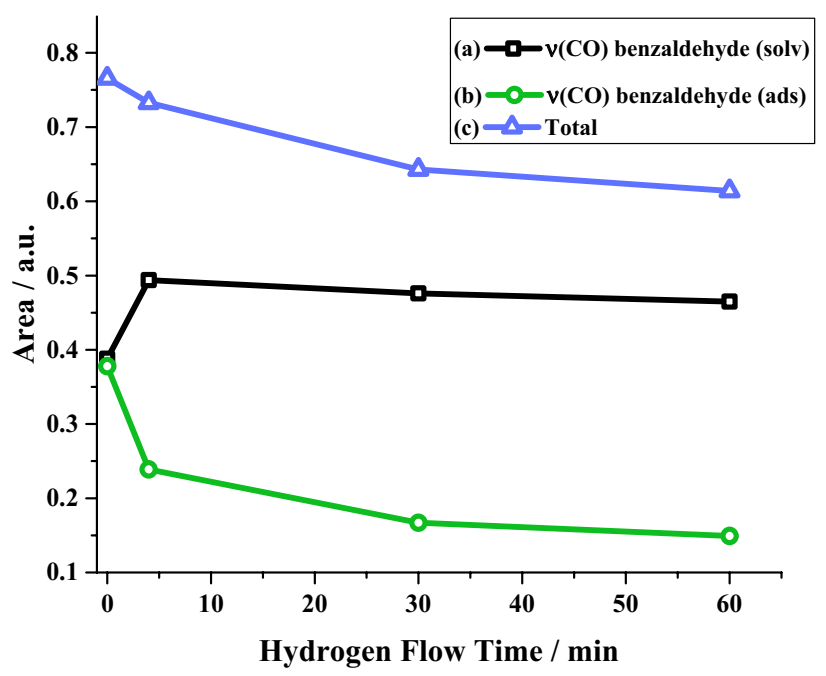

Fig. 4 Integrated area of both the liquid phase $\left(1712 \mathrm{~cm}^{-1}\right.$, a) and adsorbed $\left(1691 \mathrm{~cm}^{-1}\right.$, b) carbonyl bands of benzaldehyde. In addition, the total area associated with the carbonyl bands has been plotted (c). Up until, $\mathrm{t}=0 \mathrm{~min}$, the reaction system experiences a helium flow, allowing the adsorption system to reach equilibrium before the hydrogenation reaction is commenced 


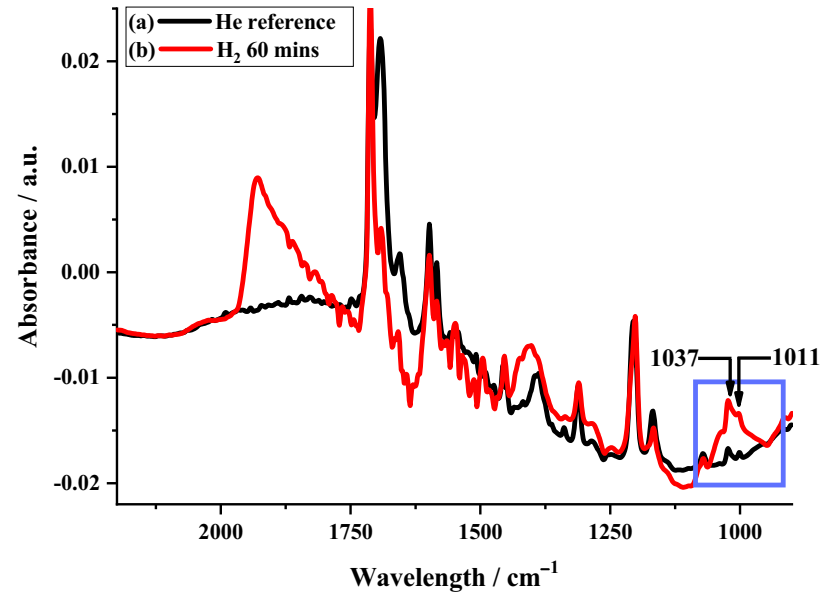

Fig. 5 ATR-IR spectra $\left(900-2200 \mathrm{~cm}^{-1}\right)$ for the interaction of benzaldehyde in cyclohexane over a $5 \mathrm{wt} \% \mathrm{Pd} / \mathrm{Al}_{2} \mathrm{O}_{3}$ catalyst $(50 \mathrm{mg})$ at $313 \mathrm{~K}$ : (a) in the presence of flowing helium ( $\mathrm{t}=0 \mathrm{~min})$ and (b) in the presence of flowing hydrogen $(\mathrm{t}=60 \mathrm{~min})$. The blue box highlights vibrational bands associated with benzyl alcohol

\subsection{ATR-IR: The Hydrogenation of Benzaldehyde to Benzyl Alcohol}

Section 3.1 establishes benzyl alcohol to be the dominant product in benzaldehyde hydrogenation over this catalyst (Fig. 2). Figure 5 compares the wide-scan ATR-IR spectrum at $60 \mathrm{~min} \mathrm{T-o-S} \mathrm{against} \mathrm{the} \mathrm{reference} \mathrm{spectrum} \mathrm{recorded} \mathrm{in}$ the absence of flowing hydrogen gas. The blue box in Fig. 5 identifies the formation of benzyl alcohol via the growth of bands at 1011 and $1037 \mathrm{~cm}^{-1}$ that correspond to the (C-O) stretch of benzyl alcohol [24]. The relative weakness of intensity of these bands is consistent with the low benzaldehyde conversion signified in Fig. 4c. It is noted that no features attributable to the presence of toluene were observed throughout the whole reaction coordinate.

\subsection{ATR-IR: CO Formation Confirms the Occurrence of the Decarbonylation Reaction}

In Sect. 3.1 it was not possible to directly identify benzene as being responsible for the mass imbalance evident in the reaction profile for the batch reactor (Fig. 2). However, due to the absence of toluene, its presence as a by-product was deduced from inspection of Scheme 1. Here we provide ancillary spectroscopic evidence to support that deduction.

Although benzene provides little in distinguishing vibrational modes for the reaction mixture under investigation, the presence of a decarbonylation pathway should manifest itself in terms of chemisorbed carbon monoxide $[20,25]$. Figure 6 a presents the ATR-IR spectrum for the helium reference run that is plotted alongside scans recording on increasing exposure to a gaseous hydrogen co-feed,

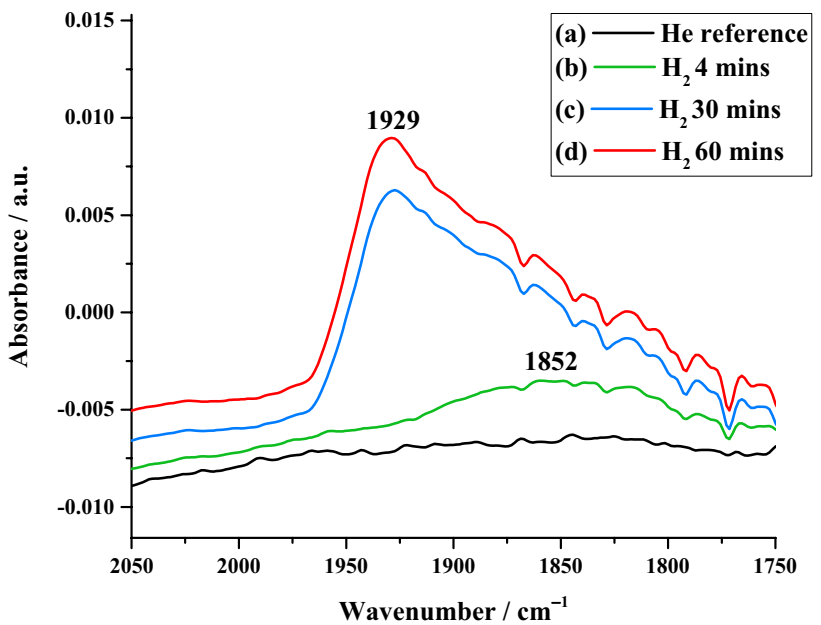

Fig. 6 (a) ATR-IR spectrum (1750-2050 $\left.\mathrm{cm}^{-1}\right)$ for the interaction of benzaldehyde in cyclohexane over a $5 \mathrm{wt} \% \mathrm{Pd} / \mathrm{Al}_{2} \mathrm{O}_{3}$ catalyst $(50 \mathrm{mg}$ ) at $313 \mathrm{~K}$ in the presence of flowing helium and after a reduction stage. The helium flow was stopped and replaced with hydrogen gas; the spectrum was monitored as a function of time-on-stream: (b) 4, (c) 30 and (d) $60 \mathrm{~min}$

Fig. 6(b-d). Figure $6 \mathrm{a}$ is featureless. However, at $\mathrm{t}=4 \mathrm{~min}$ a broad band is observed with a peak maximum at $1852 \mathrm{~cm}^{-1}$. At $\mathrm{t}=60 \mathrm{~min}$, the band has increased in intensity, with the band maximum now positioned at $1929 \mathrm{~cm}^{-1}$ and the peak skewed to lower frequencies. This feature is assigned to carbon monoxide chemisorbed to the palladium crystallites that has formed via the decarbonylation of benzaldehyde. A study conducted by Burgener et al. examining citral hydrogenation over $5 \% \mathrm{Pd} / \mathrm{Al}_{2} \mathrm{O}_{3}$ showed two bands at 1875 and $1912 \mathrm{~cm}^{-1}$ resulting from CO formation under reaction conditions [21].

Figure 6 is consistent with the presence of a decarbonylation pathway producing benzene as a by-product during the liquid phase hydrogenation of benzaldehyde over $\mathrm{Pd} /$ $\mathrm{Al}_{2} \mathrm{O}_{3}$. Moreover, if the catalyst was insufficiently reduced, $\mathrm{CO}$ binding to $\mathrm{Pd}^{+}$and $\mathrm{Pd}^{2+}$ would yield bands at approximately 2130 and $2150 \mathrm{~cm}^{-1}$ respectively [26]. As no such bands are observed (spectrum not shown), this confirms that the reduction procedure adopted was satisfactory for the catalyst.

Figure 6 also provides information on the manner of benzene formation from benzaldehyde within this reaction system. There is a degree of ambiguity about terminology in the literature concerning the formation of benzene and $\mathrm{CO}$ from benzaldehyde. Specifically, decarbonylation and hydrogenolysis appear to be used interchangeably to describe this reaction [1, 3, 27]. Hydrogenolysis can be defined as a chemical reaction whereby a carbon-carbon or a carbon-heteroatom single bond is cleaved by hydrogen [28]. Conversely, decarbonylation describes the process of removing CO [29], and thus, formation of $\mathrm{CO}$ and benzene from benzaldehyde may 
be defined as such a reaction. Nevertheless, hydrogen is not reported to be necessary for such reactions, with metal catalysts and high temperatures generally being required [30]. The possibility of a hydrogen assisted decarbonylation at low temperatures within the benzaldehyde hydrogenation system is consequently considered here.

The direct detection of $\mathrm{CO}$, as shown in Fig. 6, suggests that it is a decarbonylation reaction which is observed in this instance. However, Fig. 6a shows no CO retention by the catalyst prior to the commencement of a hydrogen flow. Given that the catalyst is in a reduced form at this stage and that the decarbonylation reaction does not have a hydrogen requirement, it would have been expected that $\mathrm{CO}$ formation would have been observed at this point. Indeed, it is only when hydrogen is introduced to the ATR-IR cell that production of $\mathrm{CO}$ is detected (Fig. 6(b-d). The exclusive occurrence of this pathway in the presence of hydrogen indicates that, in this instance, benzene formation can be more correctly considered to be a hydrogenolytic decarbonylation reaction in order to better reflect its hydrogen requirement.

\section{Discussion}

The above spectroscopic findings are linked to a reaction scheme that reflects the chemistry observed during the benzaldehyde hydrogenation reaction in the ATR-IR cell (Scheme 2). Highlighted by blue boxes in Scheme 2 are the species detectable by ATR-IR spectroscopy. Entities both in the liquid phase and adsorbed on the surface are identified. Scheme 2 illustrates that, whilst under the designated reaction conditions (Sect. 2.2), hydrogenation to afford benzyl alcohol is achieved, the subsequent hydrogenolysis of the benzyl alcohol to furnish toluene is not observed. In parallel to the hydrogenation process, hydrogenolytic decarbonylation of the benzaldehyde to form benzene and $\mathrm{CO}$ is observed, as evidenced by the binding of $\mathrm{CO}$ to the surface of the catalyst under a flow of hydrogen (Fig. 6).

Finally, the porosity and accessibility of the catalyst thin film employed in the ATR-IR experiments will be briefly considered. SEM images of an alumina supported catalyst deposited on a Ge IRE in a similar manner to that adopted in this work estimate the depth of the catalyst bed to be $\sim 100 \mu \mathrm{m}$ [31]. The approximate penetration depth of the evanescent wave of a $45^{\circ} \mathrm{Ge}$ crystal is $0.6-0.7 \mu \mathrm{m}$ [10], a value insufficient to penetrate the surface of the catalyst layer. However, under the stated conditions, as revealed by SEM [31], the catalyst layer is expected to form as a cracked and open structure that will support efficient liquid exchange. Figure 3 shows signals from both $\mathrm{BA}_{(\text {(solv })}$ and $\mathrm{BA}_{(\mathrm{ad})}$, i.e. the IR beam is interrogating both the solvent and catalyst surface. This scenario indicates that $\mathrm{H}_{2 \text { (solv) }}$ to be accessible to the catalyst surface and that hydrogen supply at the liquid/ solid interface is not expected to present significant mass transport limitations for the ATR-IR measurements considered here.

\section{Conclusions}

The liquid phase hydrogenation of benzaldehyde over a 5 wt $\% \mathrm{Pd} / \mathrm{Al}_{2} \mathrm{O}_{3}$ catalyst was examined primarily by ATR-IR spectroscopy. The following conclusions can be drawn.

- ATR-IR spectroscopy of solvated benzaldehyde present over the catalyst under a constant flow of helium revealed the presence of two carbonyl features that are assigned to solvated and adsorbed benzaldehyde. In this way, the

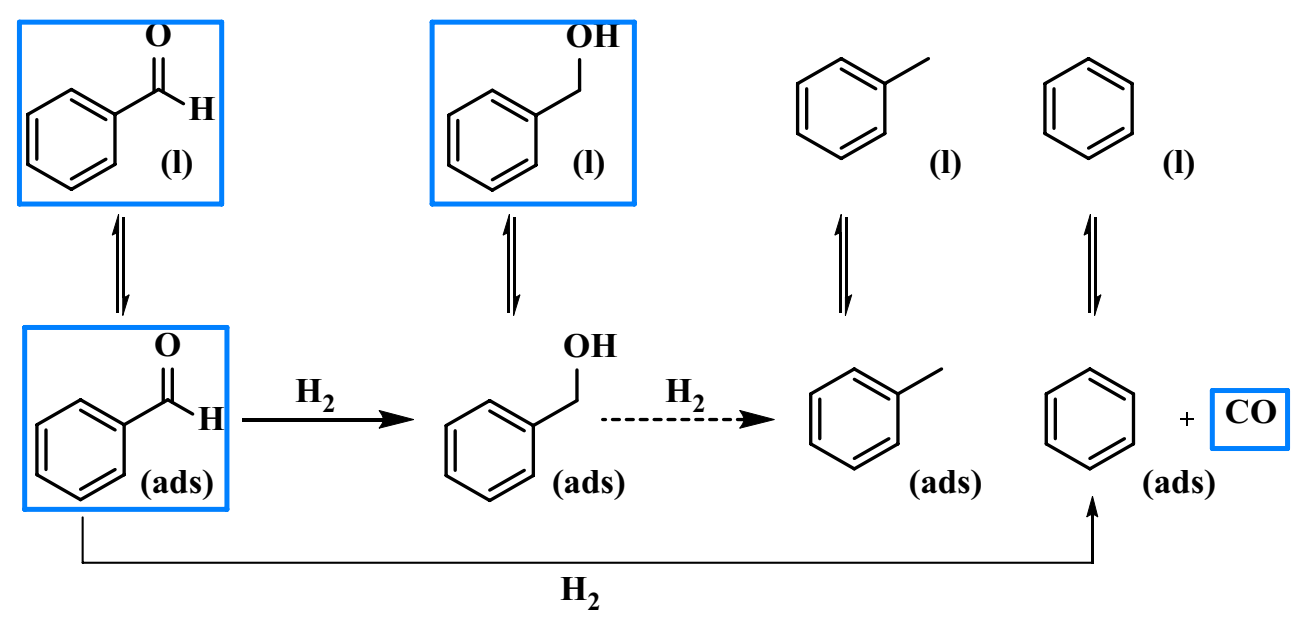

Scheme 2 Postulated reaction scheme for the hydrogenation of benzaldehyde showing the interface at the surface-liquid equilibrium. Species highlighted in blue are detectable by ATR-IR spectroscopy 
ATR-IR methodology is sampling the important equilibrium between the liquid phase and the catalyst surface.

- No hydrogenolysis to afford toluene was observed. This outcome was validated by application of a batch benzaldehyde reaction under comparable reaction conditions to the ATR-IR cell reaction.

- The introduction of solvated hydrogen to the liquid feedstream led to the observation of benzyl alcohol and CO as reaction products. The decarbonylation reaction of benzaldehyde to afford $\mathrm{CO}$ and benzene was hydrogen assisted, rendering the process a hydrogenolytic decarbonylation step.

Acknowledgements The University of Glasgow and the EPSRC (Grant Number EP/M508056/1) are thanked for the award of a Ph.D. studentship (MMcA) and project support.

Data Availability The datasets generated during and/or analysed during the current study are available from the corresponding author on reasonable request.

\section{Compliance with Ethical Standards}

Conflict of interest The authors have no conflicts of interest.

Research Involving Human and Animal Rights There were no human or animal subjects involved in this research.

Open Access This article is licensed under a Creative Commons Attribution 4.0 International License, which permits use, sharing, adaptation, distribution and reproduction in any medium or format, as long as you give appropriate credit to the original author(s) and the source, provide a link to the Creative Commons licence, and indicate if changes were made. The images or other third party material in this article are included in the article's Creative Commons licence, unless indicated otherwise in a credit line to the material. If material is not included in the article's Creative Commons licence and your intended use is not permitted by statutory regulation or exceeds the permitted use, you will need to obtain permission directly from the copyright holder. To view a copy of this licence, visit http://creativecommons.org/licenses/by/4.0/.

\section{References}

1. Perret N, Cárdenas-Lizana F, Keane MA (2011) Selective hydrogenation of benzaldehyde to benzyl alcohol over $\mathrm{Au} / \mathrm{Al}_{2} \mathrm{O}_{3}$. Catal Commun 16:159-164

2. Mironenko RM, Velskaya OB, Gulyaeva TI, Trenikhin MV, Nizovskii AI, Kalinkin AV, Bukhityarov VI, Lavrenov AV, Likholobov VA (2017) Liquid-phase hydrogenation of benzaldehyde over $\mathrm{Pd} / \mathrm{Ru} / \mathrm{C}$ catalysts: synergistic effect between supported metals. Catal Today 279:2-9

3. Saadi A, Lariasri K, Bachari K, Halliche D, Rabia C (2012) Catalytic reduction of benzaldehyde under hydrogen flow over nickel-containing mesoporous silica catalysts. Open J Phys Chem 2:73-80
4. Saadi A, Merabti R, Rassoul Z, Bettahar MM (2006) Benzaldehyde hydrogenation over supported nickel catalysts. J Mol Catal A-Chem 253:79-85

5. Nair B (2001) Final report on the safety assessment of benzyl alcohol, benzoic acid, and sodium benzoate. Int J Toxicol 20:23-50

6. Pinna F, Menegazzo F, Signoretto M, Canton P, Fagherazzi G, Pernicone N (2001) Consecutive hydrogenation of benzaldehyde over Pd catalysts: influence of supports and sulfur poisoning. Appl Catal A-Gen 219:195-200

7. Procházková D, Zámostrý P, Bejblová M, Červený L, Čejka J (2007) hydrodeoxygenation of aldehydes catalysed by supported palladium Catalysts. Appl Catal A-Gen 332:56-64

8. Blaser H-U, Malan C, Pugin B, Spindler F, Studer M (2003) Selective hydrogenation for fine chemicals: recent trends and new developments. Adv Synth Catal 345:103-151

9. Claus P (2005) Heterogeneously catalysed hydrogenation using gold catalysts. Appl Catal A-Gen 291:222-229

10. Andanson J-M, Baiker A (2010) Exploring catalytic solid/liquid interfaces by in situ attenuated total reflection infrared spectroscopy. Chem Soc Rev 39:4571-4584

11. Ortiz-Hernandez I, Williams CT (2003) In situ investigation of solid-liquid catalytic interfaces by attenuated total reflection infrared spectroscopy. Langmuir 19:2956-2962

12. Mallat T, Baiker A (2004) Oxidation of alcohols with molecular oxygen on solid catalysts. Chem Rev 104:3037-3058

13. Haider P, Kimmerle B, Krumeich F, Kleist W, Grunwadt J-D, Baiker A (2008) Gold-catalyzed aerobic oxidation of benzyl alcohol: effects of gold particle size on activity and selectivity in different solvents. Catal Lett 125:169-176

14. Campisi S, Ferri D, Villa A, Wang W, Wang D, Kröcher O, Prati L (2016) Selectivity control in palladium-catalysed alcohol oxidation through selective blocking of active sites. J Phys Chem C 120:14027-14033

15. Villa A, Ferri D, Campisi S, Chan-Thaw CE, Lu Y, Kröcher O, Prati L (2015) Operando attenuated total reflectance FTIR spectroscopy: studies on the different selectivity observed in benzyl alcohol. ChemCatChem 7:2534-2541

16. Agguire A, Collins SE (2019) Insight into the mechanism of acetonitrile hydrogenation in liquid phase on $\mathrm{Pt} / \mathrm{Al}_{2} \mathrm{O}_{3}$ by ATR-IR. Catal Today 336:22-32

17. Ortiz-Hernandez I, Owens DJ, Strunk MR, Williams CT (2006) Multivariate analysis of ATR-IR spectroscopic data: applications to the solid-liquid catalytic interface. Langmuir 22:2629-2639

18. Ortiz-Hernandez I, Williams CT (2007) In situ studies of butyronitrile adsorption and hydrogenation on $\mathrm{Pt} / \mathrm{Al}_{2} \mathrm{O}_{3}$ using attenuated total reflection infrared spectroscopy. Langmuir 23:3172-3178

19. Ferri D, Baiker A (2009) Advances in infrared spectroscopy of catalytic solid-liquid interfaces: the case of selective alcohol oxidation. Top Catal 52:1323-1333

20. Liu H, Li Z, Li Y (2015) Chemoselective hydrogenation of cinnamaldenhyde over a Pt-Lewis acid collaborative catalyst under ambient conditions. Ind Eng Chem Res 54:1487-1497

21. Burgener M, Wirz R, Mallat T, Baiker A (2004) Nature of catalyst deactivation during citral hydrogenation: a catalytic and ATR-IT study. J Catal 228(1):152-161

22. Perego C, Peralello S (1999) Experimental methods in catalytic kinetics. Catal Today 52:133-145

23. Young CL (1981) Solubility data series, Vol 5/6, Hydrogen and Deuterium. Pergamon Press, Oxford

24. Shaik RM, Al-Marri ASF, Mohri N, Barton B, Siddiqui MRH, Al-Warthan A, Labis JP, Tremel W, Khan M, Tahir MN (2017) Benzyl alcohol assisted synthesis and characterisation of highly reduced graphene oxide (HRG) @ $\mathrm{ZrO}_{2}$ nanocomposites. ChemistrySelect 2:3078-3083

25. Lear T, Marshall R, Lopez-Sanchez JA, Jackson SD, Klapötke TM, Bäumer M, Rupprechter G, Freund H-J, Lennon D (2005) 
The application of infrared spectroscopy to probe the surface morphology of alumina-supported palladium catalysts. J Chem Phys 125:174706-174713

26. Hadjiivanov K, Vayssilov GN (2002) Characterization of oxide surfaces and zeolites by carbon monoxide as an IR probe molecule. Adv Catal 47:307-511

27. Modak A, Deb A, Patra T, Rana S, Maity S, Maiti D (2012) A general and efficient aldehyde decarbonylation reaction by using a palladium catalyst. Chem Commun 48:4253-4255

28. Connor R, Adkins H (1932) Hydrogenolysis of oxygenated organic compounds. J Am Chem Soc 54(12):4678-4690

29. Clayden J, Greeves N, Warren S, Warren S, Wothers P (2001)

Organic chemistry. Oxford University Press, New York, p p1319
30. Beck CM, Rathmill SE, Park YJ, Chen J, Crabtree RH, LiableSands LM, Rheingold AL (1999) Aldehyde decarbonylation catalysis under mild conditions. Organometallics 18(25):5311-5317

31. Keresszegi C, Ferri D, Mallet T, Baiker A (2005) On the role of $\mathrm{CO}$ formation during the aerobic oxidation of alcohols on $\mathrm{Pd} /$ Al2O3: an, in situ attenuated total reflection infrared study. J Catal 234:64-75

Publisher's Note Springer Nature remains neutral with regard to jurisdictional claims in published maps and institutional affiliations. 